\title{
Understanding the effectiveness of investments in irrigation system modernisation: Evidence from Madhya Pradesh, India
}

\author{
Authors: Ranu Sinha ${ }^{1}$, Michael Gilmont ${ }^{2}$, Robert Hope ${ }^{3}$ and, Simon Dadson ${ }^{4}$ \\ ${ }^{1}$ School of Geography and the Environment, University of Oxford, Oxford, UK \& Oxford \\ India Centre for Sustainable Development, Somerville College, Oxford, UK. \\ ${ }^{2}$ Environmental Change Institute, University of Oxford, Oxford, UK. \\ ${ }^{3}$ Smith School of Enterprise and the Environment, School of Geography and the \\ Environment \& REACH Programme Director, University of Oxford, Oxford, UK. \\ ${ }^{4}$ School of Geography and the Environment, University of Oxford, Oxford, UK.
}

Corresponding author: Ms. Ranu Sinha

Email: Ranu.Sinha@some.ox.ac.uk

Word Count: 8000 


\title{
Understanding the effectiveness of investments in irrigation system modernisation: Evidence from Madhya Pradesh, India
}

\begin{abstract}
Investments in modernising irrigation infrastructure are key to enhance water security for agriculture. However, outcomes of investments are insufficiently understood, potentially limiting the future design of interventions. This article applies a fixed-effects regression model to test whether modernisation of irrigation systems in Madhya Pradesh leads to improvements in district-level yields and protection of yields against sub-basin rainfall variability. Findings suggest that investments fail to improve crop yields in districts with deficient rainfall and fail to buffer yields against monsoon variability compared to control districts with no investments. Interventions should be designed to respond to the complexities of sub-basin rainfall variability.
\end{abstract}

Keywords: water security; India; irrigation modernisation impacts; rainfall variability; food security. 


\section{Introduction}

Global debates on water security advocate that countries facing water resources challenges should invest in physical infrastructure as well as institutions for water management to reduce water-related risks (Grey and Sadoff, 2007; Grey et al., 2013; Sadoff et al., 2015). For water-insecure developing countries, investing in water-related infrastructure in the agriculture sector is expected to increase economic growth and protect against shocks from rainfall variability. India has invested in irrigation infrastructure to reduce the vulnerability of the agricultural sector to hydrological variability (Dhawan, 1993; World Bank, 2002; Duflo and Pande, 2007; Shah and Kumar, 2008). Multiple state governments in India have focussed on public investment in construction, modernisation, and rehabilitation of major and medium irrigation projects (Biswas-Tortajada, 2014; Thatte, 2017). Areas with investment in surface irrigation have seen increasing yields, changing cropping patterns, increasing gross cropped area, and transition from a mono crop regime to double cropping in comparison to areas wholly dependent on rain-fed agriculture (Planning Commission, 2011; Kumar et al., 2014; Jagdeeshan and Kumar, 2015).

Despite extensive literature on the effectiveness of irrigation in developing countries, there is little evidence on the relationship between district-level rainfall variability, investments in modernisation of irrigation infrastructure, and impacts on crop yields (Wade, 1988a; Thakkar 1999; Mosse 2006; Hope, 2007; Mollinga, 2014). Specifically, it is unclear a) how rainfall patterns vary at a sub-basin level (e.g. district to district); b) how surface irrigation investments impact crop yields at a district-scale; and c) if irrigation investments can buffer yields from district-level rainfall variability. Therefore, this paper explores whether investments in system modernisation are effective once heterogeneity in sub-basin rainfall and degree of investment levels are analysed against changes in crop yields. We build a fixed effects regression model to test the influence of irrigation investment interventions on district-level crop yields of three staple crops (paddy, wheat, and gram) within the Indian state of Madhya Pradesh. The model is based on investments made in modernization and rehabilitation of irrigation systems during the Madhya Pradesh Water Sector Restructuring Project (MPWSRP) 
funded by the World Bank (World Bank, 2005; Table 2). This new dataset, which collates high-resolution data at a sub-national and sub-basin scale, was specifically created for this study and represents one of the unique contributions of this paper. Unlike a majority of the economic analysis studies in the water and agriculture sector which use publicly available, national-level datasets to determine outcomes, this paper was able to access data at the district and sub-basin scales that are typically not available to researchers.

The MPWSRP was initiated in 2005 by the Government of Madhya Pradesh and 'aimed to improve productivity of water for sustainable growth, and poverty reduction across 31 districts in selected focus river basins of Madhya Pradesh (MP)' (World Bank, 2005; Sapre, 2014). The economy of MP is predominantly agrarian with agriculture, animal husbandry, and fisheries as the primary sectors of the state. However, there have been large-scale fluctuations in the agriculture sector's performance in recent years with agricultural growth rates as low as $-2.44 \%(2007-08)$ to more than $11.18 \%(2010-11)$ (Sapre, 2014). Therefore, by targeting investments in the water and agriculture sector in 2005 , the state government aimed to address their development objectives of income and employment generation for farmers, poverty alleviation, and agricultural growth (Government of Madhya Pradesh, 2011).

The rationale for investments in irrigation system rehabilitation was based on a hydrological basin approach (World Bank, 2005). The MP government aimed to shift the focus of its Water Resources Department (WRD) towards integrated river basin management (World Bank, 2005). MP has ten river systems (Mahi, Chambal, Sindh, Betwa, Ken, Tons, Son, Narmada, Wainganga and Tapi) (Figure 1). Irrigation systems were rehabilitated in six out of the ten river basins (Chambal, Sindh, Betwa, Ken, Tons, and Wainganga) (Figure 1). The secondary justification was to address the engineering needs of the systems. Systems that were 20 years or older, that had not been adequately maintained by the WRD, and were no longer operating at optimal standards, received investments.

\section{INSERT FIGURE 1ABOUT HERE}


To analyse the impact of the infrastructure investments made in the MPWSRP, we tested the following hypothesis:

Investments in irrigation infrastructure modernisation lead to higher crop yields and buffer yields from fluctuations in rainfall at a district-level.

We tested this hypothesis by analysing the impact of investments in irrigation rehabilitation on crop yields across 31 districts, with and without investments using a fixed effects regression model. Data on aggregated gram, paddy and wheat yields were assessed to compare variations in yield between intervention and non-intervention districts as well as differing levels of rainfall variability. Yield is an impact indicator of irrigation investment because amongst the multiple factors contributing to crop yield, access to adequate irrigation is one of the key determinants of agriculture production (Minten and Barrett, 2008; Damania et al., 2017). Therefore, improving irrigation system performance by means of investments to rehabilitate aging infrastructure is a critical production factor that can help lift the hydrological constraints on agricultural productivity (Ostrom et al., 2011). Studies have found that crops typically show the greatest yield increases when cultivation shifts from rain-fed to surface irrigation in semiarid regions (Rockstrom et al., 2010; Elliott et al., 2013). Paddy and wheat were selected because of all the cereal crops grown in MP, $80 \%$ of the cultivated land area is dedicated to the production of these crops (Government of Madhya Pradesh Economic Survey, 2014). And, of the pulses, about $60 \%$ of the cultivable area is dedicated to gram production (Government of Madhya Pradesh Economic Survey, 2014). In order to examine fluctuations in rainfall at a district level, we analysed data on rainfall patterns from 2005-2014 for all selected districts and determined standardised anomaly patterns for each district's monsoons over the last ten years.

This study, therefore, is relevant not just for Madhya Pradesh but contributes to the wider literature that examines irrigation modernisation impacts, rainfall variability, and economic outcomes in India as well as other populous, water stressed countries. Studies that examine the challenges of economic growth and rainfall variability as well as analyse the role of investments in water-related infrastructure and water institutions tend 
to utilise national, regional, and global datasets to make assertions at regional and country levels (Falkenmark, 1997; Brown and Lall, 2006; Duflo and Pande, 2007; Sadoff et al., 2015; Narayanamoorthy, 2018). These studies often overlook post-investment impacts on crop yields and the role of sub-basin variability on crop yields at a sub-national scale, as data at this scale is typically not available. In addition, studies that explore the importance of intra-seasonal precipitation variability on crop yields rarely examine more than two years of intra-annual data in one location; and often do not incorporate the combination of infrastructure and crop price effects (Veron et al., 2015; Fishman, 2016; Damania et al., 2017). This paper attempts to address these gaps in the wider literature by conducting a detailed analysis of crop yield responses to investments in irrigation rehabilitation while accounting for inter and intra-annual district-level monsoon anomalies as well as examining the influence of crop price factors on yields over a period of ten years.

Section 2 describes the methodology and section 3 describes the results. Section 4 presents a discussion of the results and limitations, and section 5 presents conclusions of the study.

\section{Methods and Data Analysis}

\section{Characteristics of the study area}

MP is the third largest state in India with a total geographical area of about 40 million hectares (ha). The state has a population of 72 million as per the 2011 Census with an estimated $36 \%$ of the rural population living below the poverty line. The economy is dominated by agriculture, which accounts for $26.5 \%$ of the Net State Domestic Product (NSDP) (Government of Madhya Pradesh, 2011). The agricultural sector employs $73 \%$ of the working population (Sapre, 2014).

MP has 10 agro-climatic zones and five main crops zones (De et al., 2001) (Table 3 ). The state also has five regions with 52,143 villages, 23,044 panchayats (village councils) and 323 development blocks in 51 districts. Districts in India are local 
administrative units that form the tier of local government just below the Indian state. The analysis in this study focuses on 31 districts that fall within the six river basins where the MPWSRP made interventions (Figure 1). We collected and analysed data at a districtscale rather than river basin scale to identify variations in impacts across different districts within a river basin. Basin level analysis alone tends to mask heterogeneity in rainfall patterns among districts within a state.

Annual rainfall in Madhya Pradesh ranges from 800 millimetres (mm) to 1,600 $\mathrm{mm}$ from west to east, occurring mainly during the monsoon (June to September) (Government of Madhya Pradesh, 2011). Historical analysis of rainfall variability indicates that the summer monsoon (June to September) in central India has changed significantly between 1950 and 2000 (Sushant, 2013). The frequency of days with heavy rainfall $(100 \mathrm{~mm} /$ day) increased from 45 to 65 days per year, while the frequency of extreme rainfall events $(150 \mathrm{~mm} /$ day $)$ has doubled from 9 to 18 days per year during this period (Sushant, 2013). In contrast, the frequency of days with moderate rainfall (e.g. between 5 and $100 \mathrm{~mm} /$ day) has decreased. An increased frequency of extreme events and erratic rainfall along with a decline in number of moderate rainfall days indicates that MP is facing high levels of hydro-climatic variability. At present, $60 \%$ of the total net sown (cropped) area in Madhya Pradesh is served by surface and groundwater sources of irrigation and $40 \%$ of the cropped area in the state is rain-fed.

\section{The Madhya Pradesh Water Sector Restructuring Project}

The MPWSRP focused on maximizing water productivity in all its uses in 495,000 ha of designed potential irrigation command areas in six basins, out of which, only half of the area was serviced with canal irrigation when the project began (World Bank, 2005). Over half of the 193,000 farms (61\%) in the project area are small farms with an average land holding size of less than one hectare. Therefore, a majority of the farmers in the study area are the poorest members of rural society in India, mainly coming from the most vulnerable caste groups, holding Below the Poverty Line (BPL) cards, and living in temporary housing. The Food and Supplies Departments of state governments in India 
issue "Below Poverty Line" ration cards to individuals who are considered to be earning an income below the official Government of India poverty line of $\$ 1.90$ per day. This card entitles individuals to be given subsidized allocations of rice and wheat by state government Public Distribution Schemes. The MPWSRP made a total investment of USD \$ 443 million across four components with the costs and objectives listed in Table 1 (World Bank, 2005). The analysis in this study will focus on Component C, as this component made investments in modernisation and rehabilitation of irrigation canals and tanks.

Upon closure in 2015, the MPWSRP modernised and rehabilitated 5 major, 21 medium, and 202 minor irrigation schemes. A major irrigation system is a system that provides irrigation to more than 5000 ha of farmland, a medium system is a system that serves 2000-4999 ha, and minor systems can serve 200-1999 ha. A total of 228 investments in system modernisation were made. This included activities such as repair works on dams and embankments, addressing seepage and drainage issues, improving boundary stones, and repairing sluice and radial gates on the infrastructure. Old canals were lined with concrete to reduce seepage and improve distribution of water. These investments represent expenditure arising from the need to repair systems where the government had failed to maintain existing irrigation structures. The project aimed to improve cropping intensity, improve irrigation efficiency of the surface irrigation canals, and improve crop production for kharif, or summer crops (i.e. paddy) and rabi, or winter crops (i.e. wheat and gram) (World Bank, 2005). The project focussed on achieving these objectives by adding new capacity to manage risk as well as restoring lost productivity benefits of older systems.

\section{Sampling Framework}

In order to compare results of crop yields and rainfall levels between the 31 districts, we developed a sampling framework. The framework was built on secondary data on: a) the size, scale, and timing of the irrigation investments made by the MPWSRP within treatment districts, b) inter and intra-annual rainfall data for 31 districts for the period 
2005-2014; and, c) average crop yield data for the three main crops across 31 districts within the same timeframe. Selection of the 228 irrigation projects was based on systems that were built before 1986 and those that exceeded certain degradation thresholds of designed performance (World Bank, 2005). Thus, some districts received more investments than others, and some received no investments.

\section{Irrigation Investment Data}

In order to analyse the 228 irrigation schemes, we obtained data on: a) the total command area of the systems; b) the percentage of irrigated area rehabilitated within each district by the project; c) the total amount of investments made by the project in USD within each district; d) the dollar amount invested per hectare in each district; and e) the start and completion year of each irrigation rehabilitation project within each district. This information is summarised in Table 2.

For the sampling framework, we divided the 31 districts into two "irrigation investment categories". Districts were classified as "Rehab" (systems that were rehabilitated by MPWSRP) and "No Rehab" (if there were no MPWSRP investments made in command areas of these districts). Districts that received rehabilitation investments only in specific parts of their command areas and not in others fell into both categories (designated with a * in Table 4 ). Within the Rehab category, districts were further divided into two investment categories. Low Rehab represents districts that had less than $10 \%$ of their irrigated area rehabilitated by investments from MPWSRP. Medium-High Rehab represents districts that had more than $30 \%$ of their irrigated area rehabilitated (Table 2 and Table 4).

The data on district-wise crop yields used in this study represents average yields from a combination of rain-fed, groundwater, and surface irrigated sources. Therefore, the yield values used for the analysis are an average of a combination of these three irrigation sources, as MP government yield data do not differentiate yields by source of irrigation. Despite this limitation, however, we can assume that there are variations in the 
types of irrigation sources utilised by farmers in different districts. The data collected on yields at the district-level includes farm plots in command areas for both Rehab and No Rehab districts. Therefore, we operate under the assumption that farmers in districts in the Medium-High Rehab category have a higher likelihood of irrigating their crops utilising surface irrigation rather than rely on rainfall and pump irrigation in relative comparison to farmers in districts that are in the No Rehab categories. We, therefore, assume yield outputs of the crops from the Medium-High Rehab and to some extent the Low Rehab districts are more likely to be from command areas with modernised, surface irrigated sources. In comparison, crops in the No Rehab districts will most likely be irrigated with groundwater or rainfall due to the absence of reliable surface irrigation supply. It is important to note the arguments put forth by Shah (2009) and others that the differentiated irrigation needs of farmers in South Asia are being increasingly met by groundwater sources rather than gravity flow from canals (Kumar and Singh 2007; Shah, 2009, p. 84; Kumar et al., 2011). Shah (2009) argues that the main factors behind the rapid decline in canal irrigation are related to the poor performance of surface irrigation systems throughout India, market failures, failure of participation of irrigating communities, and failure of public sector agencies to deliver irrigation water in the right quantity and at the right time when farmers require for their crops. In addition, the work of Molle and Berkoff (2007) indicates that when groundwater is available to farmers on demand, this offers "a security of supply" that can provide reliable irrigation when rainfall and canal supplies are variable. The fact that groundwater is so readily available to farmers has both resulted in limiting the need of surface irrigation to meet "diversified demands" for water for differing crops (Molle and Berkoff, 2007).

The MPWSRP, however, specifically aimed to address these concerns raised by Shah (2009) and others. The MPWSRP made investments in tank rehabilitation of specific deteriorated major, medium, and minor tanks in command areas within target districts with emphasis on desiltation, repairing of sluice gates, and also investing in the capacity building of Water User Associations (WUAs) to increase participation from farmers in field-level canal operation and maintenance. Palanisami et al. (2010) argue that addressing these concerns would improve adequate water supply in the tanks, 
improve storage capacity, and assist farmers in coping with the impacts of climate change in the future. In addition, registering WUAs would enable member farmers to undertake regular repairs and maintenance thereby improving usage of tank irrigation by WUAs themselves (Palanisami, 2000; Palanaisami et. al 2010). Therefore, the fact that MPWSRP targeted investments to improve canal systems enables us to assume that overall supply of irrigation water improved coinciding with increased usage of tank irrigation by beneficiary farmers in respective command areas.

Lastly, the data on yields presented in this study are lower on average in comparison to yield values from purely surface irrigated sources. This is because our data includes yield values that are not differentiated by source of irrigation. At present secondary data on crop yields solely from groundwater or surface sources at the district and farm-level is not available in Madhya Pradesh. Therefore, it was not possible for us to differentiate crop yield data from rain-fed and groundwater versus gravity irrigation sources into our analysis. Thus, the results of the empirical model can be interpreted as the treatment effect on crop yields based on a mix of irrigation sources. This suggests that our results are, if anything, underestimates of the treatment effect on yields from farms using surface irrigation. 
Inter-annual variation in the monsoon cycle is determined by the relative contribution of multiple external and internal air-sea interactions and oscillations, with heavy or less rainfall traditionally resulting in floods or droughts (Ratna et al., 2011; Neena et al., 2011). To analyse inter-annual variability in MP, we divided the 31 districts into three rainfall categories: low rainfall, average rainfall, and high rainfall. This was to determine if there was significant diversity in the inter-annual rainfall patterns among the Rehab and No Rehab districts, and to identify how many of the districts among the 31 tend to have low, average, or high rainfall. Monthly rainfall data were provided for all districts for each month (Jan - Dec) for the years 2005-2014 from the Government of Madhya Pradesh Water Resources Department. Annual averages from 2005-2014 were determined by averaging the 12 monthly rainfall values for all available rain gauge stations in each district. Once the monthly average for each year was calculated, we then calculated the ten-year average for that district and classified each district according to its corresponding rainfall zone.

If a district's 10 -year average is within $10 \%$ of the 10 -year average of all districts, then it is classified as having Average Rainfall. The boundary classification for average rainfall is between $869-1062 \mathrm{~mm}$. If a district's rainfall levels are more than $10 \%$ below the 10-year average of all the districts, then it is classified as Low Rainfall. The boundary classification for low rainfall is less than $869 \mathrm{~mm}$. When a district's 10-year average rainfall is more than $10 \%$ of the 10 -year average of the selected districts, it is categorised into the High Rainfall zone. The boundary classification for high rainfall is greater than $1062 \mathrm{~mm}$. Table 3 provides the corresponding rainfall categories for each district. The sampling framework is in Table 4. Table 4 indicates that there is heterogeneity in the inter-annual rainfall averages within the Low and Medium-High Rehab districts as well as between the Rehab and No Rehab districts. Not all districts received the same level of investment, and not all districts have the same patterns of rainfall when examined over a ten-year period. 


\section{Intra-annual Rainfall Data}

In order to determine whether investments in irrigation modernisation buffer crop yields from fluctuations in rainfall at a district-level, we examined intra-annual rainfall. As monsoon rainfall is important for determining agricultural yields and productivity, it was determined that the four monsoon months (June - September) across all ten years would be utilised to examine intra-annual variability. The rainfall dataset obtained consists of actual observed values for rainfall compiled by the Irrigation Department rather than satellite data. In order to calculate the standardised monsoon anomaly of each district, the first step was to determine the average of the observed monthly rainfall values for each district from June - September for all years from 2005-2014. Standardised anomalies generally provide more information about the magnitude of the anomalies because influences of dispersion have been removed. The second step was to calculate monthly rainfall climatology, which is the mean value of rainfall for each month over the time period 2005-2014. Rainfall anomalies for each district were computed by subtracting observed values of monthly data from the monthly average values for all 31 districts. The third step was to determine if seasonal variations are present within the monsoon months.

Standardized anomalies are calculated by dividing the rainfall anomaly values by the climatological standard deviation. Thus, the climatological standard deviation of the rainfall was calculated for each of the monsoon months for all 31 districts. Once standard deviations were determined, the standardized anomaly was determined by dividing the rainfall anomaly for the monsoon months from the standard deviation values of each respective month. The results of all the 31 standardised anomaly graphs for each district are in Figures A1-A5 and available as online supplementary materials. Lastly, we classified each year from 2005-2014 into the three rainfall zones for all 31 districts. The results of this analysis are displayed in Table 5 in Section 3. 


\section{Crop Yield \& MSP Data}

For the crop yield analysis, secondary data were compiled for each district on average yields produced in kilograms per hectare for the panel data used in the regression models. Inter-annual monsoon rainfall values for each district were also included in order to compare how yield values changed during average, low or high rainfall years. Agriculture yield data were obtained from the Madhya Pradesh Commissioner Land Records Office in Gwalior district. Data were also compiled on the Minimum Support Price (MSP) for each of these three crops from 2005-2014. MSP was added as an additional variable of analysis into the fixed effects model to test whether yields within these districts were influenced by the MSP prices for these crops.

The Minimum Support Price is a national scheme of the Government of India to protect farmers from exogenous price shocks. Within this scheme, the government declares the minimum price for specific commodities for which the government will guarantee that farmers can sell their produce. Data on the MSP values for the three crops from 2005-2014 was obtained from the Madhya Pradesh Directorate of Economics and Statistics, Department of Agriculture, Cooperation and Farmers Welfare.

\subsection{Fixed Effects Regression Model}

We tested the hypothesis by using panel data for 31 districts for the years 2005-2014. This panel consists of data on: a) crop yields for paddy, wheat, and gram, b) inter and intra-annual monsoon rainfall, c) data on the timing, size, degree of irrigation investment within districts where irrigation systems were rehabilitated by the MPWSRP, and d) annual MSP values for each crop. In order to measure the effect of the MPWSRP irrigation investment (treatment) on crop yields over time, we determined that the use of a fixed effects model would be optimal. A fixed effects model enables us to test the statistical relationship between the treatment (investments in system modernisation) and 
outcome variables (crop yields) controlling for district-level rainfall variability, variations in MSP over time, and other district-level variations.

To test whether investments in irrigation rehabilitation and modernisation lead to higher crop yields at a district-level, we estimated the following equation. This equation is estimated once for each crop (paddy, wheat, and gram):

$$
\text { Yield }_{i t}=\beta_{1} \mathrm{~T}_{i t} \mathrm{Z}_{\mathrm{i}}^{\text {Low }}+\beta_{2} \mathrm{~T}_{i t} \mathrm{Z}_{\mathrm{i}}^{\text {Average }}+\beta_{3} \mathrm{~T}_{i t} \mathrm{Z}_{\mathrm{i}}^{\text {High }}+\beta_{4} \mathrm{R}_{i t}+\beta_{5} \mathrm{P}_{t}+\mathrm{y}_{\mathrm{t}}+\mu_{i}+\varepsilon_{i t}
$$

In this equation, Yield ${ }_{i t}$ is the dependent variable of yields for each crop (paddy, wheat, and gram) where $i=$ district and $t=$ time. Yields are measured in $\mathrm{kg} / \mathrm{Ha}$ in logs. $\mathrm{T}_{i t}$ represents the treatment intensity of irrigation investment. This is measured as the cumulative command area (CCA) that was rehabilitated by the MPWSRP for each district (i) by time $(t)$. This gives the coefficient $\beta_{1}$ the interpretation of being the percent change in yields for every 1000 ha of rehabilitated CCA. We utilised this approach to identify the treatment effect, as the rehabilitation of the individual tanks, within a district, was implemented by means of successive projects, which began in different years and completed at different times. Therefore, we needed to identify exactly how much rehabilitation was completed within a given year and within a given district. The CCA rehabilitated is a good indicator to measure this. $Z_{i}$ represents the rainfall zone of the district. This is a categorical dummy variable. Therefore, $\mathrm{T}_{i t} \mathrm{Z}_{i}^{L o w}$ represents the interaction between treatment intensity and districts in the low rainfall zone. We used this interaction term to explore the differential impact of irrigation investments in districts with low, average, and high rainfall. This enables us to test whether irrigation investment had a larger impact on crop yields in districts with predominantly low rainfall compared to average or high rainfall districts. The resulting interpretation of the coefficients is that $\beta_{1}$ represents the response to treatment in low rain fall zones, $\beta_{2}$ represents the response to treatment in average rainfall zones, and so on.

$\mathrm{R}_{i t}$ represents inter-annual monsoon rainfall values in $(\mathrm{mm})$ for each district $(i)$ at time $(t) . \mathrm{P}_{t}$ is the explanatory variable representing the MSP value in (Rs./kg.) for the 
corresponding crop (e.g. paddy, wheat or gram) of the dependent variable at time $(t)$. Both monsoon rainfall and MSP values are standardised to have mean zero and standard deviation of one. These variables are standardised to facilitate comparison in their relative importance in predicting crop yields. In addition, we have found that standardizing these two variables using z-scores is an appropriate measure to avoid collinearity in analyses of their association with the outcome variable (Abraham and Sheeran, 2003; Kahan et al., 2012). ytrepresents time fixed effects. The time dummy variable picks up all the unobserved variables that may vary within the state on an annual basis, which are unaccounted for in our panel data. For instance, if the Government of Madhya Pradesh introduced new programs for agricultural inputs or technologies from one year to the next throughout the state, this variable would capture the resulting variations in crop yields. $\mu_{i}$ is the district fixed effect. This controls for unobserved heterogeneity at the district level and $\varepsilon_{i t}$ is the error term.

Lastly, our empirical analysis is based on the assumption that "treatment" (or investments in system modernisation by the MWPSRP) are randomly assigned conditional on an (unobserved) level of deterioration of past irrigation infrastructure within selected river basins. This is captured in the district fixed effect variable in our regression equation. This information was based on direct reports from the World Bank and the Madhya Pradesh Water Resources Department on how investment decisions are made. However, there may be cases where specific investment projects are selected based on socio-economic or political grounds rather than solely on technical specifications. In these cases, we assume that treatment would not be randomly assigned. This represents a limitation of the fixed effects model. In the present study, we found no evidence from government officials or World Bank representatives that selection of projects took place on political or socio-economic grounds and so we assume for the purposes of this study that treatment has been randomly assigned. 


\section{Results}

\section{Rainfall Analysis Results}

The result of the standardized monsoon anomaly plots indicates that no two districts are alike. Across the ten-year period, each of the 31 districts has a unique anomaly pattern. Secondly, the classification of each year (2005-2014) into low, average or high rainfall years according to the analysis of the intra-annual monsoon values illustrates that there are some years where the weather is consistently wet or dry, and others where the variability between districts dominates (Table 5). Therefore, water availability for the annual cropping season can vary drastically both within a monsoon season from district to district, and from one year to another within a single district.

Analysis of data from the MP Meteorology Department indicates that from 20072010, 37-41 districts experienced severe drought and rainfall deficiency ranging from 26 days to 30 days (Government of Madhya Pradesh, 2011). However, in 2007, even though a majority of districts experienced low rainfall, some districts actually experienced wet monsoons (Table 5). Districts such as Dhar, Ratlam, Shajahapur, and Dewas saw high rainfall levels with an extreme positive anomaly away from the mean. Conversely, from 2011-2013, there was a trend of relatively “wetter" monsoons across a majority of districts, but with some districts with deficient rainfall (e.g. Bhind, Shivpuri and Ujjain) (Table 5).

Based on this, we conclude that there is evidence of heterogeneity in the sub-basin hydrological climate among districts in MP, which could be influencing district-level crop yields. Multiple districts within a river basin in MP have diverse rainfall patterns within a single year and within one monsoon season. This can range from extremes of wet monsoons to dry monsoons within one cropping season. 


\title{
Fixed Effects Model Results
}

\author{
Results of Hypothesis Test
}

As we analysed three staple crops, we ran the regression separately for paddy, wheat and gram. For each crop, we ran two regressions: the first does not include time fixed effects, the second includes time fixed effects. In order to show the robustness of our results, we present the results of both regressions in Table 6 for each crop. Columns 1, 3 and 5 in Table 6 presents results of the model without time fixed effects and columns 2, 4 and 6 include time fixed effects. Results of the regression with time fixed effects are preferred as they control for external factors that changed within Madhya Pradesh over time.

The results presented in Table 6 show that for paddy and wheat, there are statistically significant results that indicate that irrigation investments improved wheat and paddy yields in districts with average rainfall. For wheat, in column 2 with year fixed effects, we see that yields improved by $2.4 \%$ for every 1000 ha of treatment. To illustrate impact of the treatment, results are applied to a specific district in our study area. Ashoknagar, for instance, is in the average rainfall zone and had 12,900 ha of command area rehabilitated by the MPWSRP by 2014. Based on the results in Table 6, we can then assume that wheat yields went up by $31 \%$ due to the irrigation investment in Ashoknagar. This increase seems reasonable, although it only explains a small portion of the increase in crop yields in Ashoknagar. Based on the secondary data collected, we know that wheat yields grew from $1086(\mathrm{~kg} / \mathrm{Ha})$ in 2005 to $2702(\mathrm{~kg} / \mathrm{Ha})$ in 2014. Therefore, other variables in our regression model may also contribute to the growth in yields in wheat for a district such as Ashoknagar. One potential contributing factor could be the MSP of wheat. Our results show that a 1 standard deviation increase in the MSP of wheat leads to a highly statistically significant $11.4 \%$ increase in wheat yields, while controlling for time fixed effects (column 2, Table 6). Here a one standard deviation increase in wheat MSP is equivalent to a Rs. 2.3 increase in the MSP, compared to a mean MSP of Rs. 11.3. 
For paddy, the treatment had a slightly larger impact than wheat with time fixed effects showing yield improved by $3.8 \%$ as a result of every 1000 ha of treatment (column 4, Table 6). For all crops, the treatment effect is larger without year fixed effects, therefore, we view the results from the regression that include the year fixed effects as the more conservative values. However, we prefer these values as they control for variations over time in Madhya Pradesh and thus represent more robust results. Therefore, in the districts with average rainfall and for the crops paddy and wheat our hypothesis is accepted.

In the case of gram, we do not find evidence that the rehabilitation program increased crop yields. This is due to the fact that there were no significant results for gram. Investments had no significant impact on gram yields in districts with average rainfall. In addition, for all three crops, treatment effects were not statistically different from zero for the high rainfall zone. This trend indicates that in districts with above average rainfall, farmers have a tendency to rely less on surface and groundwater irrigation sources. In addition, the MSP variable was not significant for the gram crop, unlike for the wheat and paddy crops. As gram is a relatively water efficient rabi crop, farmers in Madhya Pradesh tend to plant gram when there is limited access to irrigation or when rainfall is low or both. Therefore, in the model, we see that the treatment effect for gram is slightly positive and significant only in the low rainfall zone (column 6, Table 6). However, gram crop yields tend to be robust despite reduced irrigation, unlike wheat which is highly sensitive to quantity of irrigations. As a result, we see that gram does not follow the same pattern as paddy and wheat in our model. Lastly, the state government does not procure gram at the same scale as wheat and paddy and therefore we see that the MSP of gram also does not have a significant relationship to yield. As a result, farmers will tend to produce more wheat and paddy than gram in average and above average rainfall zones as well as place more emphasis on paddy and wheat production for which there is a larger scale of procurement from the government than gram production (Reddy, 2004). 
In the low rainfall zone, treatment has a very small impact on paddy and gram yield, with gram showing only a 0.25 percentage increase while paddy yields seem to go down by 0.51 percent as a result of treatment (columns 4 and 6 , Table 6). This indicates that for most districts in the high and low rainfall zones, the treatment effect was zero, except for a few instances where there was a small positive and small negative effect for gram and paddy in the low rainfall zones. In spite of the statistical significance of this result, the small size of the effect is insufficient to be of practical interest.

For the monsoon rain variable, we see that the correlation between monsoon rain and crop yields is largest for paddy. These regression results are consistent with previous research that shows that rice yields are highly sensitive to variation in rainfall. We find that a one standard deviation increase in monsoon rain causes paddy yields to rise by $6.4 \%$, whereas wheat and gram yields are unaffected (column 4). This is consistent with previous research by Saseendran et al (2000), who find that an increase in rainfall above observed values leads to an exponential increase in rice yields and a decrease in rainfall results in a constant $8 \%$ loss in yields for every $2 \mathrm{~mm} /$ day to $16 \mathrm{~mm} /$ day reduction in rainfall.

Our regression results also shed light on a current debate regarding the impact of Minimum Support Prices on crop yields. We had specifically included MSP as a variable to test the difference in influence on yields from irrigation investment versus other variables of production (e.g. crop price). Research on the impact of MSP indicates that MSP prices have often induced farmers in India to produce surplus grains (e.g. wheat) resulting in excessive stock and placing a high burden of storage of excess wheat supply on the Indian government (Gouel et al., 2016). This trend towards increasing wheat and paddy yields as a result of increasing MSP values of these crops is supported by the model. Our results indicate that a one standard deviation increase in MSP of wheat results in an increase of yields by $11.4 \%$ and for paddy an even larger $26.8 \%$ increase in yields (columns 2 and 4, Table 6). As discussed, gram is the exception to this. Our results, however, contradict work by Ali et al., (2012) who argue that "non-price factors" such as improved seed varieties, assured irrigation through tube-wells, and fertilizer are more 
important determinants of agricultural growth in paddy production than price factors (Ali et al., 2012). Our model indicates that for wheat and paddy, MSP has a higher influence on yield than monsoon rain. This finding warrants deeper analysis into the differential impact of MSP versus irrigation investment on farmer behaviour. This is out of the scope of this paper and needs to be explored in further research.

In Table 6, wheat and paddy had R-squared values of 0.63 and 0.72 , respectively; meanwhile there is a much lower R-squared for gram (0.38). This implies that our variables in the regression have good predictive power for paddy and wheat and slightly lower predictive power for gram yields in these districts.

\section{Robustness Checks on Regression Results}

In order to test the robustness of the regression results reported in Table 6, we performed a set of regression diagnostics. Specifically, we checked for multicollinearity of MSP and rainfall in the regressions presented in Table 6 . In order to test these results, we ran the variance inflation factor (VIF) diagnostic to test for multicollinearity (Marquardt, 1980; Graham, 2003; Lin, 2008). A variable which has VIF values greater than 10, merits further investigation. In order to check on the degree of collinearity, a tolerance value is calculated. This is defined as 1/VIF. A tolerance value lower than 0.1 is comparable to a VIF of 10. This then indicates that the variable could be considered as a linear combination of other independent variables. The VIF tests indicate that there is no evidence of multicollinearity.

In a previous version of the regression results, we encountered multicollinearity between rainfall and MSP when these variables were included as levels rather than as zscores. To address this issue, we converted these variables to z-scores in our baseline regression results. This is a common standardisation that is designed to reduce the impact of outliers on the regression results and also facilitates comparison between the impact of rainfall and MSP on crop yields, by putting the two explanatory variables into common units. 


\section{Discussion and Limitations}

\section{Discussion of Results}

Accounting for District-level Rainfall Variability

The intra-annual rainfall analysis reveals that no two districts are alike when it comes to its standardised monsoon anomaly. Monsoon variability dominates not only on a temporal scale but also at a spatial, sub-basin or district-scale. As farmers in Madhya Pradesh continue to rely on rain-fed and increasingly groundwater irrigation in districts where surface irrigation is absent or variable, crop yields as a result continue to be sensitive to hydrology, particularly to sub-basin rainfall variability.

The current design of investments in system rehabilitation in MP does not take into account crop sensitivity to this district-level rainfall heterogeneity. A process-driven approach (e.g. investing in modernising aging systems in selected basins) can benefit the existing distribution of infrastructure with positive results for districts facing average patterns of rainfall. However, this approach can have potential inequitable impacts for those systems in districts with dryer than average or wetter than average rainfall patterns. Therefore, it is important to not only address the structural, engineering needs of infrastructure but also design investments based on an understanding of how monsoon patterns are behaving at an inter-annual and intra-annual scale within each district. Thus, improving the ability of Irrigation Departments to reliably and flexibly deliver irrigation services adapted for diversity in localized, rainfall patterns. This finding is in agreement with existing literature that argues that investments to improve canal systems within India are not taking into account all potential costs and benefits when designing investment programs (Shah \& Kumar, 2008; Kumar, 2017). Therefore, we argue, that district-level monsoon anomalies pose a diverse set of "costs" on canal irrigation systems that needs to be considered in the design of future investment programs.

A caveat to this finding, however, is that further analysis into district-specific rainfall patterns is necessary to determine the robustness of the observed patterns over a longer time period (e.g. beyond the 10-year monsoon cycle) and therefore determine the 
types of rainfall anomaly patterns that may emerge and the types of irrigation systems that are needed. In the event that a specific rainfall pattern within a district is evident only within a 10-year period, then it may be unwise to design systems solely on sub-basin variability of that period. Although it is not possible to reliably predict future rainfall trends with $100 \%$ accuracy, it is critical to couple the engineering concerns of irrigation systems with more in-depth climatological analysis at a sub-basin level (Conway and Schipper, 2011).

\section{Limited role of irrigation infrastructure to buffer against rainfall variability}

Our analysis indicates that there is little to no effect of treatment on crop yields in low rainfall areas. This leads us to believe that crop yields in these districts are still, to some extent, coupled with rainfall variability. This also indicates that there is some reliance on rain-fed and groundwater irrigation for farmers in these districts despite rehabilitated irrigation systems. However, in order to further substantiate this finding, primary data on crop yields from groundwater withdrawals at the farm-level in gravity irrigation command areas would need to be collected and incorporated into the model.

Unfortunately, at present, this data is not available in Madhya Pradesh. Despite this limitation, the results validate and further nuance existing literature on the connections between investments in water resources development and impact on growth in agriculture dominated economies.

Specifically, studies indicate that regions where agriculture forms a major part of the economy tend to be more sensitive to hydroclimatic variability and persistent negative precipitation anomalies seem to exert a significant climate influence on GDP per capita growth (Brown et al., 2011; Khan et al., 2017). Lundqvist and Fallenmark (2010) point out that despite management and efficiency improvements in physical water management infrastructure, periods of severe water scarcity cannot be managed with "conventional measures" alone. Gilmont et al. (2018) determine that increased use of groundwater for irrigation (rather than surface sources) does not, in fact, buffer agriculture growth from rainfall variability. Literature on water resources management approaches in India 
highlights the need to resolve supply side interventions to include adaptation to the increasing likelihood of a higher frequency of extreme events (Thatte, 2017). With an expected increase in variability of the monsoon climate in India, however, tank irrigation is still considered one of the major strategies for coping with rainfall variability (Kumar et al., 2011; Mathison et al., 2013; Siderius et al., 2015). Studies in other countries have also illustrated the potential for infrastructure investments to decouple economic growth from rainfall variability (Gilmont, 2014; Damania et al., 2017). This substantiates the need to design future investments in system modernisation to adapt more effectively to localised hydrological challenges within sub-basins in India. However, it is also important to note that investments are only one of the integral instruments in a basket of other necessary legal, economic, social, and institutional reforms necessary to cope with climate change induced hydrological variability in India (Tortajada, 2014).

\section{Influence of MSP on Crop Yields}

The model indicates that MSP has a positive and highly significant influence on crop yields for wheat and paddy crops in treatment and non-treatment districts in Madhya Pradesh. This price influence is statistically larger than district monsoon rainfall factors on yield. The strong influence of MSP, however, is not necessarily a positive factor, as farmers tend to over produce crops such as wheat and paddy leading to excess supply of cheap grain crops in the Indian market. The guaranteed MSP for cereal crops may be disincentivising farmers from switching to higher value and more profitable horticulture crops for which there are no guaranteed government purchase prices. Many studies have determined that due to MSP farmers tend to prefer rice and wheat cultivation over pulses and oil seeds (Chand, 2003; Jha \& Srinivasan, 2006; Jha, 2009; Mittal \& Hariharan, 2016). Other studies that have analysed the effect of MSP on area and production of food crops state that MSP as an instrument seems to encourage wheat crops over paddy cultivation among Indian farmers (Raj and Anjugam, 2016). The MSP results advance empirical evidence to illustrate that price factors seem to have a stronger degree of influence on farmer cropping choices and as a consequence yields than rainfall. 
Previously, literature on this topic has argued that irrigation improvements, not price factors, are instrumental in enabling farmers to have a consistent source of water, leading to higher yield, improved cropping intensity, and crop diversification (Del Carpio et al., 2011). In order for the benefits of irrigation rehabilitation and modernisation to be truly realized, farmer choices around crops and water use also need to become more sustainable. Thus, the potential limiting role of MSP in influencing farmer cropping choices towards lower value cereal crops needs to be further examined.

\section{Limitations}

We identify four core limitations to this study. First, crop yield response to irrigation water is a highly complex relationship that depends on multiple factors (e.g. soil conditions, evapotranspiration rates, seepage, percolation, and drainage capacity in the canals) and socio-economic dynamics at play at a village and farm-level within individual districts as well as within the command area (Rosegrant, 1992; Mehta, 2005; Swyngedouw, 2009; Mahapatra, 2012). A major source of complexity is the suite of highly intricate village-level relationships, institutions, and processes in India that has been shown to influence agricultural productivity and outcomes of water sector reforms (Wade, 1988b; Tanka and Fuller, 2010; Maertens and Barrett, 2013). Variations from one village to another in the way irrigation systems are managed at the community-level also plays a role on variations in agricultural production (National Research Council, 1986; Wade, 1987; Meinzen-Dick et al., 2002; Mosse, 2005, 2006; Mollinga, 2010). A detailed examination of the interplay between village and farm dynamics and irrigation investments to rehabilitate existing canals, therefore, are necessary in order to further nuance our results.

Second, the actual construction quality of the systems that were rehabilitated may impact crop yield outcomes as well as the subsequent operation and maintenance of the systems by WRD engineers and WUAs once rehabilitation is completed. Third, the consequences of scarcity of water, unpredictable supply in the tail-end areas of irrigation systems can result in lower yields and lower cropping intensity. Therefore, different rules 
of water delivery and differences between actual and expected deliveries are also worthy of consideration and might be expected to impact the efficacy of the investments and the quality of crop yields (Wade, 1988a; Mahapatra, 2012; Singh et al., 2018). Lastly, the degree of reliance on groundwater irrigation will also determine how resilient crop yields are to rainfall variability as areas with high reliance on groundwater may still produce high crop yields despite lack of surface supply and/or highly variable monsoons. We were unable to test this outcome due to data limitations, however, recommend that future studies of this nature analyse farm-level crop yields from groundwater irrigation sources.

\section{Conclusions}

Integrated Water Resources Management is a process that generally does not consider the marginal benefits and costs of investments. Where marginal benefits vary by nature of the production function (yield, revenue, profit) then a more selective strategy for investment is required. This includes rainfall variability in determining where the marginal costs of infrastructure are uneconomical. Therefore, there is no guaranteed positive relationship between crop yields and investments in modernisation and rehabilitation of water-related infrastructure (e.g. surface irrigation) - instead the yield outcomes depend on the interaction between sub-basin hydrology and the infrastructure available.

Planning modernisation of systems based on multiple layers of hydrological, infrastructure and agricultural data may maximise benefits from investments. This result suggests that the traditional engineering-driven, basin-level planning model may be improved by investing in more robust systems for classifying district-level rainfall anomalies and its linkages with rainfall availability and crop yields at a district and even farm-level. However, additional data on crop yields from farm-level groundwater usage is necessary to further nuance our findings. Lastly, there is also a need to better understand productivity differences from MSP vs. surface irrigation and to understand whether price factors or irrigation availability has a stronger impact on farmer behaviour around cropping choices and water use efficiency practices. In India, understanding whether investments in irrigation modernisation reduce the vulnerability of smallholder 
farmers to climatological and agricultural risks is essential, as similar investment models have been implemented across multiple states.

\section{Acknowledgments}

We would like to thank Professor David Grey of the University of Oxford for his vision and support for this work. We also want to thank Mr. Joop Stoutjesdijk of the World Bank for his guidance and encouragement to undertake this study. We give sincere thanks to Mr. Subhankar Biswas and Mr. Vivek Bhatt of the Government of Madhya Pradesh for their valuable insights and support during the data collection process. We also want to thank Mr. Michael Athanson of the University of Oxford, Bodleian Map Room for his ArcGIS support in the design of the maps for this paper. Lastly, we would like to thank the Oxford India Centre for Sustainable Development at Somerville College, Oxford for the scholarship support. The results of the monsoon anomaly graphs and the rainfall data used are provided in an additional supplement that shows the secondary yield, investment and price data used in the analysis. This document is an output from the REACH programme funded by UK Aid from the UK Department for International Development (DFID) for the benefit of developing countries (Aries Code 201880). However, the views expressed and information contained in it are not necessarily those of or endorsed by DFID, which can accept no responsibility for such views or information or for any reliance placed on them. 


\section{References}

Abraham, C., \& Sheeran, P. (2003). Acting on intentions: The role of anticipated regret. British Journal of Social Psychology, 42, 495-511.

Ali, S., Sidhu, R., \& Vatta, K. (2012). Effectiveness of Minimum Support Price Policy for Paddy in India with a Case Study of Punjab. Agricultural Economics Research Review, 25(2).

Biswas-Tortajada, A. (2014). The Gujarat State-Wide Water Supply Grid: A step towards water security. International Journal of Water Resources Development, 1-13.

Brown, C., \& Lall, U. (2006), Water and economic development: The role of variability and a framework for resilience, Natural Resources Forum, 30, 306-317.

Brown, C., Meeks, R., Hunu, K., \& Yu, W. (2011). Hydroclimate risk to economic growth in sub-Saharan Africa. Climatic Change, 106(4), 621-647.

Chand, R. (2003) Government Intervention in Foodgrain Markets in the New Context, (Policy paper No. 19.2003). New Delhi, India: ICAR-National Institute for Agricultural Economics and Policy Research.

Conway, D., \& Schipper, E. (2011). Adaptation to climate change in Africa: Challenges and opportunities identified from Ethiopia. Global Environmental Change, 21(1), 227237.

Damania, R., Desbureaux, S., Hyland, M., Islam, A., Moore, S., Rodella, A. S., ...Zaveri, E. (2017). Uncharted Waters: The New Economics of Water Scarcity and Variability. Washington, DC: World Bank.

De, D., Singh, R.S., \& Chandra, H. (2001). Technological impact on energy consumption in rain-fed soybean cultivation in Madhya Pradesh. Applied Energy, 70(3), 193-213.

Del Carpio, X. V., Loayza, N., \& Datar, G. (2011). Is Irrigation Rehabilitation Good for Poor Farmers? An Impact Evaluation of a Non-Experimental Irrigation Project in Peru. Journal of Agricultural Economics, 62(2), 449-473.

Dhawan, B.D. (1993). The Big Dams: Claims and Counter Claims. New Delhi, India: Commonwealth Publishers.

Duflo, E. \& Pande, R. (2007): Dams. The Quarterly Journal of Economics, 122(2), 601646.

Elliott, J., Deryng, D., Müller, C., Frieler, K., Konzmann, M., Gerten, D., ... Wisser. D. (2014). Constraints and Potentials of Future Irrigation Water Availability on Agricultural 
Production under Climate Change. Proceedings of the National Academy of Sciences, 111(9), 3239-44.

Falkenmark, M. (1997). Meeting water requirements of an expanding world population. Philosophical Transaction of the Royal Society of London, 352, 929 - 936.

Fishman, R. (2016). More Uneven Distributions Overturn Benefits of Higher Precipitation for Crop Yields. Environmental Research Letters, 11(2), 7.

Gilmont, M. (2014). Decoupling dependence on natural water: Reflexivity in the regulation and allocation of water in Israel. Water Policy, 16(1), 79-101.

Gilmont, M., Hall, J., Grey, D., Dadson, S., Abele, S., \& Simpson, M. (2018). Analysis of the relationship between rainfall and economic growth in Indian states. Global Environmental Change, 49, 56-72.

Gouel, C., Gautam, M., \& Martin, W. (2016). Managing food price volatility in a large open country: The case of wheat in India. Oxford Economic Papers, 68(3), 811-835.

Graham, M. (2003). Confronting Multicollinearity in Ecological Multiple Regression. Ecology, 84(11), 2809-2815.

Grey, D. \& Sadoff, C. (2007). Sink or swim? Water security for growth and development. Water Policy, 9(6), 545-571.

Grey, D., Garrick, D., Blackmore, D., Kelman, J., Muller, M., \& Sadoff, C. (2013). Water security in one blue planet: twenty-first century policy challenges for science. Philosophical Transactions of the Royal Society A: Mathematical, Physical and Engineering Sciences, 371, 20120406.

Hope, R. (2007). Evaluating Social Impacts of Watershed Development in India. World Development, 35(8), 1436-1449.

Institute of Applied Manpower Research, Planning Commission of India. (2011). India Human Development Report 2011: Towards Social Inclusion. New Delhi: Oxford University Press.

Jagadeesan, S., \& Kumar, D. M. (2015). The Sardar Sarovar Project: Assessing economic and social impacts. New Delhi, India: Sage Publications.

Jha, S., \& Srinivasan, P.V. (2006). India-Reforming Farm Support Policies for Grains (Report Prepared for IGIDR-ERS/USDA Project: Indian Agricultural Markets and Policy). Mumbai: Indira Gandhi Institute of Development Research. 
Jha, B. (2009). Drivers of Agricultural Diversification in India, Haryana, and the Greenbelt Farms of India (Working Paper Series No. 303). New Delhi: Institute of Economic Growth.

Kahan, D.M., Peters, E., Wittlin, M., Slovic, P., Larrimore Ouellette, L., Braman, D., \& Mandel, G. (2012). The polarizing impact of science literacy and numeracy on perceived climate change risks. Nature Climate Change, 2(10), 732-735.

Khan, H., Morzuch, B., \& Brown, C. (2017). Water and growth: An econometric analysis of climate and policy impacts. Water Resources Research, 53(6), 5124-5136.

Kumar, D.M., \& Singh, O. (2007). Groundwater management in India: Physical, institutional and policy alternatives. New Delhi, India: Sage Publications.

Kumar, K., Kamala, K., Rajagopalan, B., Hoerling, M., Eischeid, J., Patwardhan, S., ...Nemani, R. (2011). The once and future pulse of Indian monsoonal climate. Climate Dynamics, 36, 2159-2170.

Kumar, D.M., Scott, C., \& Singh, O.P. (2011). Inducing the shift from flat-rate or free agricultural power to metered supply: Implications for groundwater depletion and power sector viability in India. Journal of Hydrology, 409(1), 382-394.

Kumar, D.M., Jagadeesan, M.S., \& Sivamohan, M. (2014). Positive externalities of irrigation from the Sardar Sarovar Project for farm production and domestic water supply. International Journal of Water Resources Development, 1-19.

Kumar, M. (2017). Water management in India: The multiplicity of views and solutions. International Journal of Water Resources Development, 34(1), 1-15.

Lin, F. (2008). Solving Multicollinearity in the Process of Fitting Regression Model Using the Nested Estimate Procedure. Quality \& Quantity, 42(3), 417-426.

Lundqvist, J., \& Falkenmark, M. (2010). Adaptation to rainfall variability and unpredictability: New dimensions of old challenges and opportunities. International Journal of Water Resources Development, 26(4), 595-612.

Maertens, A., \& Barrett, C. (2013). Measuring Social Networks' Effects on Agricultural Technology Adoption. American Journal of Agricultural Economics, 95(2), 353-359.

Mahapatra, S. (2012). Dynamics of irrigation management and interlinked agrarian relations: Empirical findings from a canal irrigation command in Odisha, India. Water Policy, 14(6), 957-976.

Marquardt, D. W. (1980). You should standardize the predictor variables in your regression models. Journal of the American Statistical Association, 75, 74-103. 
Mathison, C., Wiltshire, A., Dimri, A., Falloon, P., Jacob, D., Kumar, P., ...Stoffel, M. (2013). Regional projections of North Indian climate for adaptation studies. Science of the Total Environment, 468, 4-17.

Meinzen-Dick, R., Raju, \& Gulati. (2002). What Affects Organization and Collective Action for Managing Resources? Evidence from Canal Irrigation Systems in India. World Development, 30(4), 649-666.

Mehta, L. (2005). The politics and poetics of water: The naturalisation of scarcity in Western India. New Delhi, India: Orient Longman.

Minten, B., \& Barrett, C.B. (2008). Agricultural Technology, Productivity, and Poverty in Madagascar. World Development, 36(5), 797-822.

Mittal, S., \& Hariharan, V.K. (2016) Crop Diversification by Agro-climatic Zones of India-Trends and Drivers. Indian Journal of Economics and Development, 12(1), 123 32.

Molle, F., \& Berkoff, J. (2007). Water pricing in irrigation: Mapping the debate in the light of experience. In Molle, F., \& Berkoff, J. (Ed.), Irrigation water pricing: the gap between theory and practice. (pp. 21-93). Wallingford, UK: CABI.

Mollinga, P. (2010). The Material Conditions of a Polarized Discourse: Clamours and Silences in Critical Analysis of Agricultural Water Use in India. Journal of Agrarian Change, 10(3), 414-436.

Mollinga, P. (2014). Canal irrigation and the hydrosocial cycle: The morphogenesis of contested water control in the Tungabhadra Left Bank Canal, South India, Geoforum, 57, 192-204.

Mosse, D. (2005). The rule of water: Statecraft, ecology and collective action in south India. New Delhi, India: Oxford University Press.

Mosse, D. (2006). Rule and Representation: Transformations in the Governance of the Water Commons in British South India. The Journal of Asian Studies, 65(1), 61-90.

Narayanamoorthy, A. (2018). Financial performance of India's irrigation sector: A historical analysis. International Journal of Water Resources Development, 34(1), 116131.

National Research Council. (Ed.). (1986, April). Proceedings of the conference on common property resource management, Washington, DC. Washington, DC: National Academy Press. 
Neena, J. M., Suhas, E. \& Goswami, B. N. (2011). Leading role of internal dynamics in the 2009 Indian summer monsoon drought. Journal of Geophysical Research, 116, D13103.

Ostrom, E., Lam, W., Pradhan, P., \& Shivakoti, G. (2011). Improving irrigation in Asia: Sustainable performance of an innovative intervention in Nepal. Cheltenham, UK: Edward Elgar.

Palanisami, K., Meinzen-Dick, R., \& Giordano, M. (2010). Climate Change and Water Supplies: Options for Sustaining Tank Irrigation Potential in India. Economic and Political Weekly, 45(26/27), 183-190.

Palanisami, K. (2000). Tank Irrigation - Revival for Prosperity. New Delhi, India: Asian Publication Services.

Planning, Economics and Statistics Department. (2011). Annual Plan 2011-12. Bhopal: Government of Madhya Pradesh.

Planning, Economics and Statistics Department. (2014): Economic Survey 2013-2014. Bhopal: Government of Madhya Pradesh.

Qureshi, M. E., Grafton, R. Q., Kirby, M. A., \& Hanjra, M. (2011). Understanding irrigation water use efficiency at different scales for better policy reform: A case study of the Murray-Darling Basin, Australia. Water Policy, 13(1), 1-17.

Raj, S., \& Anjugam, M. (2016). Wallop of Minimum Support Price on Food Crops in India. Indian Journal of Agricultural Economics, 71(3), 415.

Ratna, S. B., Sikka, D. R., Dalvi, M. \& Ratnam, J. V. (2011). Dynamical simulation of Indian summer monsoon circulation, rainfall and its interannual variability using a high resolution atmospheric general circulation model. International Journal of Climatology, $32,1927-1942$.

Reddy, A., (2004). Consumption Pattern, Trade and Production Potential of Pulses. Economic and Political Weekly, 39(44), 4854-4860.

Rockstrom, K., Wani, B., Hatibu, O., \& Qiang. (2010). Managing water in rain-fed agriculture. Agricultural Water Management, 97(4), 543-550.

Rosegrant, M. (1992). The impact of irrigation on production and income variability: Simulation of diversion irrigation in the Philippines. Agricultural Systems, 40(1), 283302.

Sadoff, C.W., Hall, J.W., Grey, D., Aerts, J.C.J.H., Ait-Kadi, M., Brown, C., ... Wiberg, D. (2015). Securing Water, Sustaining Growth (Report of the GWP/OECD Task Force on Water Security and Sustainable Growth). Oxford, UK: University of Oxford. 
Saleth, R. M., \& Amarasinghe, U. A. (2010). Promoting irrigation demand management in India: Options, linkages and strategy. Water Policy, 12(6), 832-850.

Sapre, A. (2014). Madhya Pradesh: Does Agriculture Determine the State's Growth Trajectory?. Margin: The Journal of Applied Economic Research, 8(1), 39-57.

Saseendran, S., Singh, K., Rathore, L., Singh, S., \& Sinha, S. (2000). Effects of Climate Change on Rice Production in the Tropical Humid Climate of Kerala, India. Climatic Change, 44(4), 495-514.

Shah, Z., \& Kumar, M. D. (2008). In the midst of the large dam controversy: Objectives, criteria for assessing large water storages in the developing world. Water Resources Management, 22, 1799-1824.

Shah, T. (2009). Taming the anarchy: Groundwater governance in South Asia [Proquest eBook central]. Retrieved from: https://ebookcentral.proquest.com/lib/oxford/detail.action?docID=592494.

Siderius, C., Boonstra, H., Munaswamy, V., Ramana, C., Kabat, P., van Ierland, E., \& Hellegers, P. (2015). Climate-smart tank irrigation: A multi-year analysis of improved conjunctive water use under high rainfall variability. Agricultural Water Management, 148, 52-62.

Singh, A., Visha Kumari, V., Gupta, R., Singh, P., \& Solomon, S. (2018). Efficient Irrigation Water Management in Sugarcane Through Alteration of Field Application Parameters Under Subtropical India. Sugar Tech, 20(1), 21-28.

Swyngedouw, E. (2009). The Political Economy and Political Ecology of the Hydro Social Cycle. Journal of Contemporary Water Research \& Education, 142(1), 56-60.

Sushant, (2013). Impact of Climate Change in Eastern Madhya Pradesh, India. Tropical Conservation Science, 6(3), 338-364.

Tankha, S., \& Fuller, B. (2010). Getting things done: Bureaucratic and entrepreneurial approaches to the practice of participatory water management reforms in Brazil and India. Water Policy, 12(1), 84-103.

Thakkar, H. (1999, August). Assessment of Irrigation in India. Paper prepared for Thematic Review IV.2, World Commission on Dams.

Thatte, C. (2017). Water resources development in India. International Journal of Water Resources Development, 34(1), 16-27.

Tortajada, C. (2014). Water infrastructure as an essential element for human development. International Journal of Water Resources Development, 1-12. 
Verón, S. R., D. de Abelleyra, \& D. B. Lobell. (2015). Impacts of Precipitation and Temperature on Crop Yields in the Pampas. Climatic Change, 130(2), 235-45.

Wade, R. (1987). The management of common property resources: Finding a cooperative solution. World Bank Research Observer, 2(2), 219-234.

Wade, R. (1988a). The management of irrigation systems: How to evoke trust and avoid prisoner's dilemma. World Development, 16(4), 489-500.

Wade, R. (1988b). Village republics: Economic conditions for collective action in South India. Cambridge, UK: Cambridge University Press.

World Bank. (2002). World Development Report 1994: Infrastructure for Development. Washington, DC: World Bank.

World Bank. (2003). World Bank Water Resources Sector Strategy: strategic directions for World Bank engagement. Washington, DC.: World Bank.

World Bank. (2005). India - Madhya Pradesh Water Sector Restructuring Project. Retrieved from: http://documents.worldbank.org/curated/en/2004/08/5054072/indiamadhya-pradesh-water-sector-restructuring-project-india-madhya-pradesh-water-sectorrestructuring-project. 